\title{
Num desporto com valores: Construir uma sociedade mais justa
}

\author{
Sports with values: Constructing a fairer society
}

\section{J. Vasconcelos-Raposo}

EDITORIAL | EDITORIAL

A sociedade que atualmente se constrói, no mundo moderno, alicerça-se num conjunto de valores que são, na sua essência, os pilares do funcionamento dos sistemas de economia de mercado. Estas mudanças requerem que repensemos o sistema de ensino, cuja estrutura curricular é, ainda, ineficiente a dar resposta a tais alterações, uma vez que persiste em validar quase que exclusivamente as áreas de formação associadas às necessidades da indústria e do mundo financeiro, intimamente associado ao retorno rápido e altamente lucrativo. A importância atribuída às atividades desportivas e até mesmo à saúde, também tende a estar associada aos setores geradores de mais-valias, sejam esses a indústria química como a que está associada ao exercício físico e estas vão desde o negócio dos suplementos alimentares à sapatilha passando pelos serviços sofisticados dos SPAS e ginásios. Tudo isto é pensado e realizado sem ter em conta aquilo que deve, verdadeiramente, ser tido como relevante para a felicidade dos cidadãos.

Nos tempos que correm, tipificados pela crise de valores socioculturais e pelo que parece ser o esgotamento do modelo económico construído na base da acumulação desenfreada de riqueza, importa repensar o papel que as atividades desportivas podem e devem desempenhar na sociedade em geral e isso só poderá ser feito de forma adequada através da pesquisa. Assim, neste editorial deixamos ficar aquelas que nos parecem ser áreas carenciadas no que à pesquisa diz respeito e nesse sentido deixando anunciado o quanto desejaríamos ver submetidos à Motricidade artigos nas áreas que de seguida aborda- mos. Importa esclarecer que alguns destes temas estiveram na base da minha intervenção enquanto docente no curso de educação física e desporto e em alguns aspetos reflete aquela que foi a bibliografia de base para essas unidades curriculares.

São várias as correntes teóricas que defendem que através das atividades físicas podemos desenvolver os valores inerentes aos processos que garantem a funcionalidade e a reprodução das sociedades alicerçadas numa economia de mercado, e que têm por base as noções de sucesso, progresso, materialismo e conformidade externa. Sem que os cidadãos sejam devidamente educados sobre este conjunto de valores, torna-se particularmente difícil promover o Desenvolvimento de qualquer Sociedade. A tese que defendemos é que deverá existir uma maior formação dos cidadãos para que estes possam de forma esclarecida beneficiar com o seu envolvimento em Atividades Físicas. Dados os ganhos socioeconómicos que advém deste tipo de comportamento a educação e promoção de cidadania deverão ser esclarecedores e integradores dos saberes já acumulados sobre os estilos de vida saudáveis, mas não só. Só com o desenvolvimento de políticas de cidadania e de saúde preventiva é que se tornará possível acelerar o processo de integração dos princípios básicos inerentes ao civismo, tal como este serve de base a qualquer sistema democrático onde a solidariedade social é um valor e uma prática preponderante, tal como essa se alicerça nos princípios socioculturais que servem como pilares para as múltiplas opções comportamentais com que nos deparamos no nosso dia-a-dia. Os verdadeiros pilares

José Vasconcelos-Raposo. Diretor da Revista Motricidade; Universidade de Trás-os-Montes e Alto Douro, Vila Real, Portugal.

E-mail: editor.motricidade@gmail.com 
socioculturais dos países de língua portuguesa são maioritariamente os princípios da ética cristã.

No presente, vivemos períodos de crise. No discurso político-ideológico fala-se da crise tal como ela vai acontecendo associada ao sector económico-financeiro, mas a crise a que nos referimos transcende esse contexto, por que nos referimos à crise implantada no domínio dos valores humanos, tão esquecidos pela classe política que se instalou nas cadeiras do poder. Para criar as condições necessárias para a promoção da felicidade dos cidadãos não é suficiente a implementação de programas económicos alicerçados em políticas de austeridade, para salvaguardar os interesses do grande capital, nem de políticas de investimento sem tomar em consideração as caraterísticas das populações a serem afetadas por esse tipo de ações. Há muito que os modelos economicistas são questionados, na medida em que as sociedades que ignoram os direitos dos seus cidadãos, tal como estes se fundamentam na satisfação e qualidade de vida, têm vindo a acentuar as desigualdades sociais, verificando-se um acentuado aumento do número de pobres e diminuindo o número de ricos para aumentar o número dos muito ricos e isto sem esquecer o acelerado ritmo de crescimento do "exército de desempregados". Em suma, não se faz desenvolvimento socioeconómico sem que este seja acompanhado de mudanças na mentalidade das pessoas e isto implica um processo de aprendizagem de novos valores, de modo a que as pessoas possam adaptar-se convenientemente ao novo tipo de exigências do sistema sociocultural que se pretende construir num mundo que é, cada vez mais, global.

A sociedade do futuro não pode ser pensada em termos da herança histórico-cultural das sociedades onde nos inserimos. O futuro tem os seus pilares naquelas que são as práticas de hoje, independentemente do contexto onde elas se inserem. Neste editorial procuramos apresentar argumentos que levem a que os pesquisadores do fenómeno desportivo tomem em consideração aquilo que consideramos urgente pesquisar através das lentes de um ethos que emerge de quem vive intensamente o mundo das emoções desse fenómeno sociocultural que é o desporto. Assim, de seguida apresentamos um conjunto de considerandos que deverão ser tomados em consideração no contexto das atividades físicas e desportivas e que devem intencionalmente integrar qualquer tipo de programas de atividades físicas dirigidas para as populações em geral, mas de uma forma muito específica quando concebidos para os mais jovens. A abrangência destas áreas do saber é de tal forma extensa que não é possível abordá-las no limitado espaço de que dispomos. Assim, e com o propósito de ser objetivo e claro na apresentação das nossas ideias, propomo-nos abordar, apenas, a questão da mudança das mentalidades e como a prática desportiva é um elemento fundamental para se atingir esse objetivo, desde que devidamente planificado e objetivado nas políticas desportivas e educativas, assim como na oferta de atividades para a comunidade em geral e para todos os programas que abranjam os jovens.

A Educação Física, a Atividade Física, o Exercício e o Desporto são aspetos fundamentais para a formação e qualidade de vida dos cidadãos e das próprias sociedades. A Educação Física, apesar de fazer parte dos curricula escolares, é vista no contexto escolar como algo secundário às outras disciplinas do plano de estudos escolares. A Atividade Física e o Exercício, há muito que foram identificados como elementos centrais para a promoção e manutenção da saúde e já existe evidência científica que demonstra que esta desempenha um papel ativo nos processos de restituição da saúde.

O Desporto, ao longo da História tem sido instrumentalizado como ideologia subjetiva para que aqueles que estão no poder possam prolongar-se nesse exercício. Parte dessa instrumentalização pode ser identificada na retórica que reproduz a ideia de que a prática desportiva é promotora de hábitos de saúde. Essa afirmação é apenas metade da realidade daquela de que nos podemos aperceber através 
dos conhecimentos adquiridos pela pesquisa científica. O Desporto é um complemento do processo promotor de hábitos de saúde e de civismo desde que oferecido e supervisionado por profissionais devidamente treinados nesta área de intervenção. Este é um aspeto frequentemente ignorado nos estudos que pretendem avaliar a relação entre atividade física e qualquer aspeto associado à qualidade de vida dos cidadãos. Assim, recomendamos que os estudos no futuro integrem como variável independente a formação dos profissionais que atuam nesta área. Dos estudos preliminares que temos realizado deparamo-nos com a realidade de que a formação académica hoje oferecida ao nível do ensino superior requer particular atenção para que estes profissionais possam ser bem-sucedidos na transmissão dos valores que abaixo passamos a descrever.

As sociedades do futuro requerem que os seus cidadãos se tipifiquem em torno dos seguintes aspetos: Entusiasmo, cooperação, lealdade, amizade, autocontrolo, alerto, autoiniciativa, intencionalidade, condicionamento, habilidade, espírito de equipa, firmeza/ atitude, autoconfiança e nobreza competitiva. A literatura nos domínios da excelência apresenta como requisitos para o sucesso dos cidadãos estes parâmetros/ valores, mas na prática eles servem bem mais que os interesses pessoais, na medida em que servem, também, para guiar qualquer processo de construção de uma sociedade onde seja possível que a vasta maioria dos seus membros tenham acesso às condições para aspirar a serem felizes na nova tipologia de sociedade que está em construção, outros diriam em "ebulição".

Abaixo apresentamos os valores que devem guiar a prática profissional dos profissionais que intervêm na área da Educação Física, Atividade Física, Exercício e Desporto aquando da conceção e oferta de atividades:

Entusiasmo: É essencial na medida em que um indivíduo entusiasmado intervém como elemento estruturador dos outros que participam nas mesmas atividades. Este é um valor que podemos promover com as atividades de grupo e direcionadas para a comunidade em geral. Implica promover, especialmente entre os jovens, a ideia que devem envolver-se nas iniciativas e atividades, nas suas e nas dos outros, apenas quando acreditam que podem ser bem-sucedidos na sua entrega. Em suma, promover a importância do trabalho, quer para assegurar o bem-estar pessoal como o coletivo.

Cooperação: De alguma forma este valor está associado ao entusiasmo e consiste em desenvolver nos cidadãos a capacidade de analisar as "coisas" segundo a perspetiva que os outros defendem, de forma a se encontrarem estratégias de ação que sejam mobilizadoras da maioria dos participantes. É privilegiar a equipa. Isto não implica abdicar dos objetivos pessoais. Aqui desejamos promover a ideia de que os índices de rendimento de cada um só tem significado real quando contextualizado ao nível da comunidade em que o indivíduo se insere.

Lealdade: Este valor adquire-se através da promoção da consistência entre as ações e o discurso individual (autorrespeito) como valor integrador dos comportamentos e atitudes, onde o elemento valorizado para a integração do indivíduo nas ações de grupo sejam os valores que defende, tendo por base o princípio básico do respeito pelos outros. Nas sociedades ocidentais a preponderância do individualismo existe em desequilíbrio com os que privilegiam o bem-estar da comunidade em geral. Assim, apesar de a participação ser ao nível dos desportos coletivos ou individuais há um conjunto de valores e de práticas que lhes atribui um valor real. É a sociedade em geral que valoriza os níveis de prestação, em suma, é a sociedade que confere valor às práticas, quer sejam individuais quer sejam coletivas e fá-lo em função dos valores que pretende ver salvaguardados.

Amizade: Resulta da estimulação mútua entre as pessoas que se associam com o propósito de levar a cabo, com sucesso, uma tarefa qualquer. São ingredientes deste valor os seguintes elementos: a) respeito mútuo; b) devoção ao que se assumiu como projeto conjunto; c) dedicação e sinceridade para com as pessoas com quem se participa nas atividades 
(espírito de equipa); d) ser-se verdadeiro para com os outros. O mero profissionalismo, por si só, não produz resultados, especialmente no contexto do desporto onde o imediatismo do resultado tende a ser transformado em maior valor comercial do atleta. Aqui, tal como constatamos no que se refere à lealdade, a amizade como valor e para ser entendida como tal deverá ser projetada para a comunidade mais imediata em que se insere o atleta: a claque do seu clube. É esta que por sua vez serve de meio para a construção mais lata dessa projeção de humanismo. É, em parte, o reconhecimento da relação de amizade entre os jogadores e a claque que leva a que estes sejam admirados e apreciados, mesmo pelos membros das equipas rivais.

Autocontrolo: Tomar consciência do papel real que se tem nas atividades em que se participa. É compreender que o todo produz, sempre, mais e melhor que o indivíduo. Através da prática desportiva é possível transmitir aos jovens a norma comportamental de que a nossa liberdade, concomitantemente, acaba onde começa a dos outros, mas também se expande quando os outros livremente aderem às nossas iniciativas.

Alerto: Integrar as atividades com a atitude de dar o seu contributo e concomitantemente aprender algo de novo para poder melhorar as suas capacidades. Associado ao desenvolvimento da mestria (ou excelência) implica uma procura constante para identificar e aprender como a sua melhoria contribui para o aumento da eficácia e da eficiência do coletivo. Este princípio é essencial para o desenvolvimento da ideia de progresso desde que as intervenções dos educadores e dos técnicos desportivos tenham como preocupação central a orientação cognitiva para a mestria: todas as experiências são oportunidades para se aprender algo mais que nos vai permitir ir mais além naquilo em que optamos aplicar os nossos esforços.

Autoiniciativa: Cultivar a capacidade e a habilidade de tomar decisões sozinho, o desejo em assumir riscos para redefinir o limite das suas capacidades. Isto implica que necessita- mos educar promovendo a motivação intrínseca de modo a que daí advenham as vantagens do auto-ensino-aprendizagem. Este valor reveste-se da maior importância na medida em que associa a procura constante para se ser melhor (diferente) sem que para isso seja necessário espezinhar os outros. Promover a ideia que entre nós e os nossos sucessos está apenas a nossa força de vontade e a determinação em querer ir mais além e que essa força deverá depender do compromisso que assumimos perante nós próprios e de que as metas são alcançáveis, desde que sejamos realistas, trabalhadores e disciplinados no trabalho.

Intencionalidade: Implica desenvolver a habilidade de resistir às tentações e manter a direção dos esforços para se atingir os objetivos que foram definidos como critério de sucesso. Todo o comportamento é intencional. Assim, importa treinar os jovens desde muito cedo sobre as vantagens da definição de objetivos. Esta habilidade não é apenas relevante para o contexto da prática desportiva. Na medida em que a intencionalidade comportamental é o âmago do comportamento, os profissionais que intervêm na área da Educação Física, do Exercício e do Desporto deverão assumir a responsabilidade de educar, intervindo ativamente no processo da gestão do tempo a que os jovens estão sujeitos no seu dia-a-dia.

Condicionamento: Refere-se ao equilíbrio estabelecido entre o exercício físico, o descanso e os hábitos alimentares. Da interação destes resulta uma formação moral, mental e física adequada às exigências do mundo produtivo, especialmente daqueles que ambicionam posições de liderança. Com a combinação destes fatores consegue-se o desenvolvimento da resistência mental. Este aspeto alicerça-se na autodisciplina. Mas, mais uma vez, estes princípios deverão ser transmitidos como parte integrante da formação teórico-prática que deverá fazer parte dos conteúdos da unidade curricular de educação física que se oferece nas escolas.

Habilidade: Desenvolvimento do conhecimento necessário para executar eficiente (com 
o menor esforço possível) e eficazmente (conseguindo os objetivos previamente definidos) as tarefas inerentes às ações em causa. Implica estar preparado para melhor interpretar e, consequentemente, responder às situações de surpresa. Da prática desportiva deverá aprender-se como com o trabalho disciplinado e devidamente orientado se desenvolve a inteligência, tal como esta pode ser aferida através das capacidades que o indivíduo apresenta em contextos específicos. O importante é que se consciencialize os jovens do processo que conduz a essas estratégias para a resolução de problemas.

Espírito de equipa: Ser-se capaz de negociar os interesses pessoais em função dos do coletivo, é saber como as vitórias do coletivo também são veículo para a promoção pessoal. A realidade da sociedade contemporânea é de tal forma complexa que requer níveis de intervenção dificilmente ao alcance de um só indivíduo. É com base nesta constatação que tão frequentemente somos expostos aos apelos para a constituição de equipas multidisciplinares, para que os sucessos possam ser alcançados o mais eficientemente possível.

Firmeza/Atitude: Ser firme e ter atitude é serse aquilo que se é estando à vontade em qualquer situação. Por outras palavras, é nunca estar em conflito consigo mesmo. É ser-se possuidor de um conjunto de valores orientadores e aplicáveis às múltiplas atividades em que os indivíduos optam por se envolver. O que aqui se apresenta é inerente ao processo de desenvolvimento de uma orientação cognitiva para a mestria e como esta tem por base a motivação intrínseca.

Autoconfiança: É ter respeito sem se ter medo, ser confiante é saber que nos preparamos o melhor possível para a tarefa com que nos deparamos. É ter a consciência que quem trabalha sempre alcança. Mais uma vez, o tipo de experiências que podem ser vividas pelos jovens no contexto da educação física, porque construídas a partir das sensações físicas associadas ao sucesso das realizações motoras e tal como estas se expressam nas emoções típicas de quem tem sucesso, representam um registo de tal forma poderoso que mais facilmente podem ser generalizáveis para os restantes contextos em que os jovens participam.

Nobreza Competitiva: É procurar ser-se amanhã melhor do que se é hoje, algo que se faz com base numa motivação intrínseca. É, em suma, a paixão de fazer bem feito tendo como referência as prestações já realizadas por si, assim como pelos outros. Este valor tem por base uma visão humanista do ser humano. $\mathrm{O}$ importante é termos a certeza que tudo fizemos para a cada dia que passa podermos ser, enquanto pessoas detentoras de um estatuto social, melhor do que fomos no dia anterior. É nunca se assumir que as coisas são estanques e que o que temos hoje não é permanente e que para o mantermos é requerido um esforço diário e assim potenciarmos as probabilidades de as termos no amanhã. Em suma, é também na nobreza competitiva que manifestamos a nossa solidariedade social: o melhor de nós próprios.

Com base nestes catorze valores procuramos desenvolver nos jovens o princípio deontológico que o Sucesso é obtido como a consequência natural de muito trabalho e ao longo de muito tempo. Sem este tipo de compromisso temporal o que se consegue são êxitos, que normalmente estão associados ao fator sorte. Em suma, na vida, tal como nas atividades desportivas reconhecem-se as seguintes formas para alcançar o sucesso: 1) através do trabalho (quem trabalha honestamente tem sempre sucesso); 2) nunca estar satisfeito com o nível de prestação atingido (procurar de uma forma sistemática redefinir os seus limites); 3 ) ser paciente e saber esperar pelo momento em que se culminarão os esforços (que ocorre no futuro).

O conceito de Progresso fundamenta-se em noções quantitativas assim como nas orientações cognitivas e temporais que os sistemas socioculturais promovem.

Quando visto aos olhos da economia de mercado o progresso tem um significado específico. Em termos quantitativos, as pessoas estão sujeitas a um conjunto de estímulos que 
visam promover o consumo, na medida em que este se apresenta como o fiel da saúde das economias em causa. Assim, as pessoas procuram ter mais e melhor. Porém esta procura de se ter "cada vez mais" deverá alicerçar-se na aceitação de valores básicos e que deverão ser preservados, através da reprodução cultural, de modo a salvaguardar a integridade sociocultural dos sistemas em que nos inserimos. Por outras palavras, procuramos educar as pessoas no princípio de que as mudanças são necessárias, que todo e qualquer indivíduo é capaz de influenciar esses processos, mas que estas, para serem eficazes, deverão ocorrer preferencialmente, na ausência da revolução. Em suma, o bem-estar do indivíduo é o pilar do bemestar da sociedade em geral.

Relativamente às orientações cognitivas $\mathrm{e}$ temporais, todas as sociedades tendem a privilegiar uma das seguintes três: passado, presente e o futuro. Para assegurarmos o progresso dos sistemas socioeconómicos, alicerçados em princípios de igualdade e justiça social, importa desenvolver nos jovens, desde os primeiros anos de escolaridade, uma orientação para o futuro. Também neste domínio as atividades desportivas revestem-se da maior importância na medida em que a aprendizagem das habilidades motoras se deverá fazer por etapas, o que implica, por parte do docente, uma gestão por fases na relação ensino/ aprendizagem. A participação em jogos ou competições também devem ser fundamentadas na definição individual de objetivos. Esta prática visa desenvolver simultaneamente as capacidades de atenção exigidas ao nível da capacidade de concentração, assim como no desenvolvimento da motivação intrínseca, requisito imperioso para o desenvolvimento da excelência, seja qualquer for o âmbito de aplicação.

Quanto à dimensão Materialista impõe-se afirmar que este é um direito básico de cada indivíduo, na medida em que em última instância da análise o que este conceito implica é que todos deverão ser compensados com algo de concreto e compatível com o seu esforço, suas capacidades e em função das suas presta- ções. Um bem material é tudo quanto pode ser quantificável, nomeadamente definir como objetivo correr 100 metros em 10 segundos e conseguir tal proeza. Ter um salário adequado às mais-valias associadas ao trabalho desenvolvido tendo como referência tanto as habilidades requeridas para a realização das tarefas (presente) como no desenvolvimento das capacidades para executá-las (todo o processo de formação: passado). Com a prática desportiva eficazmente promoveremos o materialismo como um bem na medida em que sem este se torna difícil o desenvolvimento da motivação intrínseca que no contexto do sistema social em que nos inserimos tenham ganho um significado acrescido para o envolvimento dos indivíduos em qualquer atividade.

Finalmente, nenhuma sociedade tolera a total liberdade dos seus cidadãos ou membros. Daí que a Conformidade Externa seja um requisito fundamental para assegurar, simultaneamente, a integração social dos indivíduos e da sociedade no seu todo. Por esta razão, através da definição da filosofia de participação nas atividades desportivas se definem como prioridades a noção de representatividade (personalidade coletiva). Como alunos, ao vestirem a camisola da escola, do colégio, da universidade ou do clube são, cada um em si, é a representação viva do todo (todos) que se constitui e renova na identificação e comunhão em torno dos mesmos símbolos ou agente de ação. Através desta prática torna-se possível desenvolver o respeito pelas expectativas da comunidade em que se inserem, nomeadamente: 1) a família, 2) os amigos, 3) grupo social, 4) grupo religioso, 5) grupo de trabalho, e 6) as comunidades a que pertence. Sem se desenvolverem estes sentimentos básicos dificilmente se poderão desenvolver outros de âmbito mais abrangente como é, por exemplo, o sentimento de Nacionalidade.

Através das relações estabelecidas entre atletas e treinadores e como estes, por sua vez, respondem às expectativas da comunidade em geral, os jovens aprendem que os seus comportamentos serão tanto mais livres quanto mais 
estiverem em conformidade com o bem-estar comum.

Para além destes aspetos prioritários para orientação das atividades desportivas a serem implementadas pelos órgãos competentes, é ainda de tomar em consideração o fato que o grau de exigência académica deverá ser elevado e como tal será necessário proporcionar aos discentes a possibilidade de descansarem ativamente. A atividade física, para além de estruturadora, serve também como forma de combater a alienação inerente ao trabalho repetitivo que na maioria das vezes é monótono, para além de decorrer em lugares onde graças à ausência dos valores aqui descritos é rico em conflitos entre colegas e onde, por vezes, a competência de uns é objeto de inveja por parte dos outros.

Tanto quanto nos é dado a observar, nenhuma atividade oferece a riqueza e a complexidade de dinâmicas que visam a promoção destes valores ideológicos como as atividades desportivas. Se assim é, por que razão os governos não valorizam esta componente da formação dos cidadãos?

A resposta requer mais compromisso para com as questões assim referidas, assim como uma praxis científica mais "implicada". Quanto ao envolvimento da classe governante somos da opinião que a sua atitude reflete a falta de formação e informação que aqui apresentamos como urgente. Sem este esforço, quer ao nível da pesquisa quer no desenvolvimento de ações educativas, continuaremos a assistir à instrumentalização do desporto. A mudança que preconizamos requer que a sua gestão seja feita por indivíduos cujo grau de conhecimentos sobre a complexidade do fenómeno desportivo seja suficientemente rico, para que pelo menos entendam a razão de ser dos argumentos que aqui sugerimos.

Estas são áreas difíceis de serem estudadas mas estamos certos que em breve poderemos partilhar a alegria de sermos veículo para a apresentação de resultados à comunidade científica através da Motricidade.

(c)) EY-Nc Todo o conteúdo da revista Motricidade está licenciado sob a Creative Commons, exceto quando especificado em contrário e nos conteúdos retirados de outras fontes bibliográficas. 